\title{
The epidemiology of tuberculosis in children in Australia, 2003-2012
}

$\mathrm{T}$ uberculosis (TB) in children has received increasing attention during the past decade, and the World Health Organization first estimated the global burden in 2012. In 2014, it announced that there had been 550000 cases of TB in children aged $0-14$ years in $2013,{ }^{1}$ but acknowledged that limitations to case detection meant that this was likely to be an underestimate. ${ }^{2}$ While children with TB are not a major source for disease transmission, $\mathrm{TB}$ is an important cause of childhood morbidity and mortality in settings where TB is endemic; further, an incident TB case in a young child is an important sentinel indicator of recent transmission in their community. ${ }^{3,4}$ The strategic plan for TB control in Australia recognises the incidence of TB in Australian-born children as a useful indicator for enhanced surveillance in high-risk groups and for monitoring progress in eliminating $\mathrm{TB}$ in the Australian-born population. 5,6

The incidence of TB in Australia has been low and stable for decades, with reported rates of 6.8 and 5.8 cases per 100000 population for 1990 and 2012 respectively. ${ }^{6}$ Recent immigrants from TB-endemic countries account for most cases now detected. ${ }^{7}$ Investigations of children from immigrant families have found a high prevalence of infection with $\mathrm{Myco-}$ bacterium tuberculosis. ${ }^{8}$ As a detailed analysis of the epidemiological characteristics of the national burden of TB in children in Australia has not been published, we aimed to determine the incidence and epidemiology of TB in this population over the past decade.

\section{Materials and methods}

The notification of TB is mandatory in Australia, and all cases are reported to the National Notifiable Diseases Surveillance System (NNDSS), which coordinates national disease surveillance under the auspices of Communicable Diseases Network Australia

\section{Abstract}

Objective: To describe the burden of and trends in paediatric tuberculosis (TB) in Australia between 2003 and 2012.

Design: A retrospective analysis of TB data from the National Notifiable Diseases Surveillance System (NNDSS) on TB in children (under 15 years of age) during the 10-year period, 2003-2012.

Results: TB notifications in Australia during the study period included 538 children (range, $37-66$ cases per year), representing $4.6 \%$ of the total TB case load during the period (range, 3.8\%-5.8\% each year). Place of birth was recorded for 524 patients (97.4\%); of these, 230 (43.9\%) were born in Australia, 294 (56.1\%) overseas. The average annual notification rate was 1.31 (95\% Cl, 1.20-1.43) cases per 100000 child population. The rate was higher for overseas-born than for Australian-born children $(9.57[95 \% \mathrm{Cl}$, 8.51-10.73] v 0.61 [95\% Cl, 0.53-0.69] cases per 100000 children. The overall rate was highest among those aged $0-4$ years. The annual notification rate was three times higher for Indigenous children than for nonIndigenous Australian-born children. Of 427 patients (79.4\% of total) for whom the method of case detection was recorded, $37.0 \%$ were detected by contact screening, $8.7 \%$ by post-arrival immigration screening, and $54.3 \%$ by passive case detection. Pulmonary TB was the most common diagnostic classification (64.7\% of patients). The most common risk factors were close contact with a TB case and recent residence in a country with a high incidence of TB. Treatment outcomes were satisfactory; $89.4 \%$ of children had completed treatment or were cured.

Conclusions: The burden of paediatric TB in Australia is low but has not changed over the past decade. The highest rates are among children born overseas, emphasising the important role of immigration screening as Australia aspires to eliminate TB.

(CDNA). ${ }^{5}$ All medical professionals, laboratories and other health practitioners are required by state and territory public health legislation to notify cases of TB to the relevant health departments. Under the National Health Security Act 2007, which permits the exchange of health information between federal and state and territory health departments, deidentified data for TB cases that fulfil the national case definition are transferred to the NNDSS. ${ }^{9}$

Data for all children aged $0-14$ years diagnosed with TB and reported to the NNDSS between 1 January 2003 and 31 December 2012 were included in our analysis. De-identified data for age, sex, Indigenous status, country of birth, year of arrival, residency status, site of disease, case classification, method of case identification, risk factors, laboratory results and treatment outcomes were provided. The definitions used by CDNA for TB case classification and treatment outcomes, as well as for residency and immigration status, are listed in Box 1.

Analysis was performed with Stata 9.0 (StataCorp). Proportions of categorical variables were compared using the Fisher exact test. Incidence rates and 95\% confidence intervals were calculated. Notification rates were calculated using estimated resident population data from the Australian Bureau of Statistics, ${ }^{10,11}$ including population data for the Indigenous Australian population. ${ }^{12,13}$ National TB case load and rates were obtained from the online NNDSS application for generating summary data. ${ }^{14}$

\section{Ethics approval}

Approval for the investigation was granted by CDNA, and ethics approval was granted by the 
1 Definitions used by Communicable Diseases Network Australia for tuberculosis (TB) case classification, and for residency and immigration status

Case classification

- New case: A patient who has never been treated for TB, or who was treated for less than a month

- Relapse following treatment in Australia: A patient previously treated for TB in Australia, declared cured or treatment completed, who is subsequently diagnosed with TB

- Relapse following treatment overseas: A patient previously treated for TB overseas, declared cured or treatment completed, who is subsequently diagnosed with TB

- TB following partial treatment: A patient who is deemed to have completed a partial course of treatment, in Australia or overseas, who is subsequently diagnosed with TB

\section{Australian residency/immigration status}

- Refugee/humanitarian: A person in humanitarian need overseas, or a person already in Australia who arrived on a temporary visa or in an unauthorised manner, and is claiming asylum

- Permanent resident: A person who holds a permanent visa and is usually resident in Australia

- Visitor: A person entering Australia temporarily for tourism, to visit family and friends, to undergo prearranged medical treatment, or for business-related purposes

- Overseas student: A person studying or seeking study, training or skills development in Australia

- Unauthorised person: A non-citizen unlawfully present in Australia

- Residents of Papua New Guinea covered by the Torres Strait Treaty who have accessed TB treatment with Queensland Health

Australian Capital Territory Health Human Research Ethics Committee (reference ETH.1.14.025).

\section{Results}

A total of 538 cases of TB in children were notified in Australia between 2003 and 2012, representing 4.6\% of the total case load for that period (Box 2). The average annual notification rate for children was 1.31 cases per 100000 child population, ranging from 0.92 in 2003 to 1.65 per 100000 children in 2006 . These rates should be compared with overall case notification rates of 5.0 per 100000 and 5.9 per 100000 total population in 2003 and 2006 respectively. ${ }^{14}$ Case classification was reported for $97.4 \%(524 / 538)$ of child notifications, and $97.7 \%$ of these $(512 / 524)$ were new cases. Of the remaining 12 cases, seven relapsed after full treatment in Australia, two after partial treatment in Australia, and three after treatment overseas. The greatest number of notified cases were from Victoria, and the lowest from Tasmania; the notification rate was highest in the Northern Territory.

\section{Distribution by age, sex and site of disease}

The age of the patient was reported in all notified cases. The average annual notification rates were significantly higher for those aged 0-4 years than for those aged 5-9 years $(P=0.0004)$ or $10-14$ years $(P=0.03)$. Just over half the patients $(51.7 \%, 278 / 538)$ were girls. The anatomical site of disease was recorded for $97.2 \%(523 / 538)$ of notified cases; pulmonary disease was the most frequently reported site in all age bands. Eight of the 13 patients with TB meningitis were less than 5 years old (Box 3 ).

\section{Tuberculosis notifications by population subgroup}

Box 4 and Box 5 list the case numbers and annual case notification rates by place of birth. A country of birth was reported for $97.4 \%(524 / 538)$ of patients; of these, $44 \%(230 / 524)$ were born in Australia, including 37 Indigenous children (of whom 20 were notified in the NT). The annual notification rate among Australian-born children was higher for Indigenous than for non-Indigenous children (1.70 [95\% CI, 1.20-2.34] v 0.56 [95\% CI, 0.48-0.65] per 100000 population).

Annual notification rates were significantly higher for overseas-born children than for Australian-born children (Box 4). Of the 294 notifications for children reported as born overseas, the highest number came from Papua New Guinea (64 patients) and the Sudan (59 patients) (Box 5). Data on the year of arrival were available for $97.6 \%$ of the patients reported as born overseas (287/294); $40.4 \%(119 / 294)$ of these cases were notified within a year of their arrival in Australia, 65.6\% within 2 years, and $85.0 \%$ within 5 years (Box 6). Residency status was available for $77.8 \%(229 / 294)$ of the overseas-born children: $36 \%(83 / 229)$ had refugee or humanitarian status, 35\% (81/229) were permanent residents, and $20 \%(46 / 229)$ were children diagnosed while accessing health care treatment in the Torres Strait Treaty Zone. Eight of the remaining 19 children were visitors, four were unauthorised arrivals, one was an overseas student, and six were classified as "other" (with no further information).

\section{Case detection and prevalence of known risk factors}

Data on the method of case detection were available for $79.4 \%(427 / 538)$ of children. Most cases (54.3\%, 232/427) were diagnosed by passive case detection after clinical presentation. Active screening identified further cases: $37.0 \%$ of cases (158/427) were detected by contact screening and $8.7 \%$ (37/427) by onshore post-arrival immigration screening. Contact with an infected person was reported for $34 \%(78 / 232)$ of patients diagnosed after clinical presentation, and for $22 \%(8 / 37)$ of those detected by immigration screening. Although 158 cases were recorded as having been detected by contact screening, a contact was not identified in $19 \%$ of these 
2 Notified cases of tuberculosis (TB) in children (aged 0-14 years), and case notification rates in Australia, 2003-2012

\begin{tabular}{|c|c|c|c|c|c|c|c|c|c|}
\hline & NSW/ACT & NT & Qld & SA & Tas & Vic & WA & Australia* & $\begin{array}{l}\text { National TB case load (child } \\
\text { cases as percentage) }\end{array}$ \\
\hline 2003 & 15 & 4 & 4 & 2 & 0 & 11 & 1 & 37 (0.92; 0.65-1.27) & 985 (3.8\%) \\
\hline 2004 & 10 & 0 & 13 & 0 & 0 & 18 & 6 & 47 (1.17; 0.86-1.56) & 1062 (4.4\%) \\
\hline 2005 & 17 & 1 & 5 & 1 & 1 & 31 & 7 & $63(1.57 ; 1.21-2.01)$ & 1086 (5.8\%) \\
\hline 2006 & 18 & 2 & 12 & 0 & 0 & 29 & 5 & $66(1.65 ; 1.28-2.10)$ & $1220(5.4 \%)$ \\
\hline 2007 & 21 & 8 & 5 & 2 & 0 & 13 & 5 & 54 (1.35; 1.01-1.76) & 1131 (4.8\%) \\
\hline 2008 & 16 & 3 & 7 & 1 & 1 & 25 & 3 & $56(1.40 ; 1.06-1.82)$ & $1217(4.7 \%)$ \\
\hline 2009 & 16 & 0 & 7 & 2 & 0 & 23 & 7 & 55 (1.37; 1.04-1.79) & $1305(4.2 \%)$ \\
\hline 2010 & 16 & 5 & 10 & 3 & 0 & 7 & 8 & 49 (1.22; 0.91-1.62) & $1365(3.6 \%)$ \\
\hline 2011 & 13 & 1 & 17 & 4 & 0 & 18 & 8 & $61(1.52 ; 1.17-1.96)$ & $1384(4.4 \%)$ \\
\hline 2012 & 15 & 2 & 10 & 3 & 0 & 15 & 5 & $50(1.25 ; 0.91-1.65)$ & 1317 (3.8\%) \\
\hline Total & 157 & 26 & 90 & 18 & 2 & 190 & 55 & 538 (1.31; 1.20-1.43) & $12074(4.6 \%)$ \\
\hline
\end{tabular}

Five-year case notification rates (per 100000 children per year, with 95\% Cl), 2003-2007

\begin{tabular}{lccccccccc} 
& NSW/ACT & NT & Qld & SA & Tas & Vic & WA & Australia \\
\hline Cases & 81 & 15 & 39 & 5 & 1 & 102 & 24 & 267 \\
Rate & $1.17(0.93-1.45)$ & $4.71(2.64-7.77)$ & $0.97(0.69-1.32)$ & $0.35(0.14-0.82)$ & $0.21(0.01-1.15)$ & $2.12(1.73-2.58)$ & $1.18(0.76-1.76)$ & $1.37(1.21-1.54)$
\end{tabular}

Five-year case notification rates (per 100000 children per year, with 95\% Cl), 2008-2012

\begin{tabular}{lcccccccc} 
& NSW/ACT & NT & Qld & SA & Tas & Vic & WA & Australia \\
\hline Cases & 76 & 11 & 51 & 13 & 1 & 88 & 31 & 271 \\
Rate & $1.07(0.84-1.33)$ & $3.32(1.66-5.94)$ & $1.16(0.86-1.52)$ & $0.90(0.47-1.53)$ & $0.21(0.01-1.16)$ & $1.75(1.40-2.16)$ & $1.39(0.95-1.97)$ & $1.32(1.16-1.48)$ \\
\hline *In parentheses: rates per 100 000 per year $(95 \% \mathrm{Cl})$. & & & & &
\end{tabular}

3 Sites of disease, notified cases and rates of tuberculosis (TB) by 5-year age bands

\begin{tabular}{|c|c|c|c|c|}
\hline & \multicolumn{4}{|c|}{ Age group } \\
\hline & $0-4$ years & $5-9$ years & $10-14$ years & Total \\
\hline Rate per 100000 children $(95 \% \mathrm{Cl})$ & $1.58(1.38-1.81)$ & $1.08(0.92-1.27)$ & $1.27(1.09-1.47)$ & $1.31(1.20-1.43)$ \\
\hline \multicolumn{5}{|c|}{ Sites of disease (number, as percentage of age group) } \\
\hline Pulmonary only & $121(56 \%)$ & $68(47 \%)$ & $83(47 \%)$ & $272(50.6 \%)$ \\
\hline Pulmonary plus other sites & $25(12 \%)$ & $29(20 \%)$ & $22(13 \%)$ & $76(14.1 \%)$ \\
\hline Extrapulmonary only & $67(31 \%)$ & $43(29 \%)$ & $65(37 \%)$ & $175(32.5 \%)$ \\
\hline Lymph node & & & & $113(21.0 \%)$ \\
\hline Disseminated TB & & & & $19(3.5 \%)$ \\
\hline Pleural & & & & $32(5.9 \%)$ \\
\hline Bone/joint & & & & $22(4.1 \%)$ \\
\hline Meningeal & & & & $13(2.4 \%)$ \\
\hline Peritoneal & & & & $7(1.3 \%)$ \\
\hline Genitourinary & & & & $5(0.9 \%)$ \\
\hline Not recorded & $3(1 \%)$ & $6(4 \%)$ & $6(3 \%)$ & $15(2.8 \%)$ \\
\hline Total & $216(40.1 \%)$ & 146 (27.1\%) & 176 (32.7\%) & 538 \\
\hline
\end{tabular}


4 Selected characteristics of Australian-born and overseas-born children with tuberculosis

\begin{tabular}{|c|c|c|c|c|c|c|}
\hline & \multicolumn{3}{|c|}{ Born in Australia } & \multirow[b]{2}{*}{ Born overseas } & \multirow{2}{*}{$\begin{array}{l}\text { Birthplace } \\
\text { unknown }\end{array}$} & \multirow[b]{2}{*}{ Total } \\
\hline & Indigenous & Non-Indigenous & Total & & & \\
\hline \multicolumn{7}{|l|}{ State or territory* } \\
\hline NSW/ACT & 6 & 76 & $82(53 \%)$ & $73(47 \%)$ & 2 & 157 \\
\hline NT & 20 & 1 & $21(81 \%)$ & $5(19 \%)$ & 0 & 26 \\
\hline Qld & 8 & 6 & $14(16 \%)$ & 75 (84\%) & 1 & 90 \\
\hline SA & 3 & 8 & $11(61 \%)$ & 7 (39\%) & 0 & 18 \\
\hline Tas & 0 & 1 & $1(50 \%)$ & $1(50 \%)$ & 0 & 2 \\
\hline Vic & 0 & 90 & $90(50 \%)$ & $100(50 \%)$ & 11 & 190 \\
\hline WA & 0 & 11 & $11(20 \%)$ & $44(80 \%)$ & 0 & 55 \\
\hline Australia & 37 & 193 & $230(43.9 \%)$ & $294(56.1 \%)$ & 14 & 538 \\
\hline $\begin{array}{l}\text { Annual case notification rates, } \\
\text { per } 100000 \text { children }(95 \% \mathrm{Cl})\end{array}$ & $1.70(1.20-2.34)$ & $0.56(0.48-0.65)$ & $0.61(0.53-0.69)$ & $9.57(8.51-10.73)$ & & $1.31(1.20-1.43)$ \\
\hline \multicolumn{7}{|l|}{ Presentation } \\
\hline Clinical presentation & $11(30 \%)$ & $85(44 \%)$ & $96(43 \%)$ & $129(57 \%)$ & 7 & 232 (43.1\%) \\
\hline Contact tracing & $16(43 \%)$ & $91(47 \%)$ & 107 (70\%) & $47(31 \%)$ & 4 & $158(29.4 \%)$ \\
\hline Screening & 0 & 1 & 1 & $36(97 \%)$ & 0 & 37 (6.9\%) \\
\hline No data & $10(27 \%)$ & $16(8 \%)$ & $26(24 \%)$ & $82(76 \%)$ & 3 & (20.6\%) \\
\hline \multicolumn{7}{|l|}{ Risk factors } \\
\hline Household contact & $29(78 \%)$ & $120(62 \%)$ & $149(57 \%)$ & $114(43 \%)$ & 0 & $263(48.9 \%)$ \\
\hline $\begin{array}{l}\text { Past travel to or through, or } \\
\text { residence in a high-risk } \\
\text { country or countries }^{\dagger}\end{array}$ & $3(8 \%)$ & $32(17 \%)$ & $35(15 \%)$ & $190(84 \%)$ & 1 & $226(42.0 \%)$ \\
\hline \multicolumn{7}{|l|}{ Microbiology results } \\
\hline $\begin{array}{l}\text { Positive sputum culture } \\
\text { (number, percentage of } \\
\text { cultures) }\end{array}$ & $7 / 10$ & $14 / 27$ & $21 / 37$ & $57 / 97$ & $1 / 1$ & 79/135 [59\%] \\
\hline Any culture-positive results & $26(70 \%)$ & $114(59 \%)$ & $140(41 \%)$ & $204(59 \%)$ & 1 & $345(64.1 \%)$ \\
\hline \multicolumn{7}{|l|}{ Treatment outcome $e^{\ddagger}$} \\
\hline $\begin{array}{l}\text { Completed treatment or } \\
\text { cured }\end{array}$ & $34(92 \%)$ & $186(96 \%)$ & $220(96 \%)$ & $260(88 \%)$ & 1 & $481(89.4 \%)$ \\
\hline Defaulted from treatment & 0 & 2 & 2 & 2 & 0 & 4 \\
\hline Died of tuberculosis & 1 & 0 & 1 & 4 & 0 & 5 \\
\hline Died of other cause & 0 & 1 & 1 & 1 & 0 & 2 \\
\hline Interrupted treatment & 1 & 0 & 1 & 0 & 0 & 1 \\
\hline Still under treatment & 1 & 0 & 1 & 6 & 0 & 7 \\
\hline $\begin{array}{l}\text { Transferred out of Australia } \\
\text { or not followed up }\end{array}$ & 0 & 4 & 4 & 19 & 0 & 23 \\
\hline Treatment failure & 0 & 0 & 0 & 0 & 1 & 1 \\
\hline
\end{tabular}

Except for state or territory data, percentages are column percentages; percentages $<5 \%$ are not given. $*$ The denominator is the number of cases with known place of birth. $\dagger$ For at least 3 months (cumulative) at any time during the patient's life, and where the country is not their country of birth. $\ddagger$ No data on outcome available for 14 cases.

cases $(30 / 158)$. There were 111 cases with no recorded information about the method of detection, and $44 \%$ (49/ 111) of these were reported to have had contact with an infected person.

Overall, a household or other close contact with TB was identified in 263 cases $(48.8 \%)$, and $226(42.0 \%)$ reported at least 3 months' cumulative travel to or residence in at least one high-risk country that was not their country of birth (Box 4). Sixty-eight children had both of these risk factors for TB. Five children were reported to be infected with HIV, but data on the number of patients who had been tested for HIV were not available.

\section{Culture and drug susceptibility}

A sputum culture was known to have been prepared for $25.1 \%$ 
5 Notified cases and case notification rates of tuberculosis for frequently reported countries of birth, by residency status

\begin{tabular}{|c|c|c|c|c|c|c|}
\hline Country of birth & $\begin{array}{c}\text { Cases } \\
2003-2007\end{array}$ & $\begin{array}{c}\text { Rate } \\
2003-2007\end{array}$ & $\begin{array}{c}\text { Cases } \\
2008-2012\end{array}$ & $\begin{array}{c}\text { Rate } \\
2008-2012\end{array}$ & $\begin{array}{l}\text { Total } \\
\text { cases }\end{array}$ & $\begin{array}{c}\text { Average case } \\
\text { notification rate* }\end{array}$ \\
\hline Australia & 103 & $0.55(0.45-0.67)$ & 127 & $0.66(0.55-0.79)$ & 230 & $0.61(0.53-0.69)$ \\
\hline Papua New Guinea & 23 & $262.56(166.44-393.96)$ & 41 & 377.18 (270.67-511.69) & 64 & $326.03(251.08-416.34)$ \\
\hline Somalia & 8 & $249.22(107.60-491.07)$ & 6 & $276.50(101.47-601.82)$ & 14 & $260.22(142.27 .436 .61)$ \\
\hline Ethiopia & 7 & $154.87(62.26-391.09)$ & 4 & $65.04(17.72-166.53)$ & 11 & $103.1(51.46-184.45)$ \\
\hline Sudan & 48 & 213.05 (157.09-282.47) & 11 & $47.66(23.79-85.28)$ & 59 & $129.36(98.47-166.86)$ \\
\hline Egypt & 15 & $162.87(91.16-268.62)$ & 3 & $22.62(4.67-66.12)$ & 18 & $80.1(47.48-126.60)$ \\
\hline Philippines & 6 & $11.78(4.32-25.64)$ & 10 & $11.77(5.64-21.64)$ & 16 & $11.77(6.73-19.12)$ \\
\hline India & 4 & $7.10(1.94-18.18)$ & 11 & 9.19 (4.59-16.45) & 15 & $8.52(4.77-14.06)$ \\
\hline Others & 40 & & 57 & & 97 & \\
\hline Total overseas born & 151 & 11.52 (9.76-13.51) & 143 & $8.12(6.84-9.57)$ & 294 & $9.57(8.51-10.73)$ \\
\hline
\end{tabular}

$(135 / 538)$ of children with $\mathrm{TB}$, $59 \%(79 / 135)$ of which were positive for M. tuberculosis; this represented $15 \%$ of all notified cases (Box 4 ). The yield from sputum culture was similar for Australian-born and overseas-born patients. The criteria that determined whether sputum was collected from children with suspected TB were not recorded. A sputum culture result was recorded for $34.2 \%$ of children with pulmonary (with or without extrapulmonary) disease $(119 / 348)$, of which $66 \%$ (78/119) were culture-positive. Of the 175 children classified as having only extrapulmonary disease, sputum culture results were available for $9 \%(16 / 175)$, of which one was culture-positive.

Results of susceptibility testing were available for $29.4 \%(158 / 538)$ of notified cases; $78.5 \%$ of tested isolates $(124 / 158)$ were fully susceptible to first-line anti-TB drugs. Eight children presented with multidrugresistant TB (MDR-TB), of whom six were under 4 years of age; seven of these children were from Papua New Guinea, one from Ethiopia. The prevalence of MDR-TB among all children with $\mathrm{TB}$ was thus $1 \%(8 / 538)$, or $5 \%(8 / 158)$ among those for whom susceptibility test results were available. Of the 46 children treated under the Torres Strait Treaty, 40 were culture-positive: $12 \%(5 / 40)$ of these children had monoresistant TB, 17\% (7/40) MDR$\mathrm{TB}$, and $47 \%$ (19/40) fully susceptible
TB; there were no susceptibility data for the remaining nine cases.

\section{Treatment outcomes}

Treatment outcome was classified as either "cured" or "successfully completed treatment" for $89.4 \%(481 / 538)$ of children; seven were still undergoing treatment, while 23 had transferred out of Australia or were not followed up at the end of the data collection period (Box 4). Five children died of $\mathrm{TB}$, one an Australian-born Indigenous child with fully drug-sensitive TB. The other four deaths were of children from Papua New Guinea with smear-positive pulmonary $\mathrm{TB}$, three of whom had additional sites of disease (meningeal, peritoneal and disseminated TB). One was a relapsed case of MDR-TB, while the others were new cases with fully drug-susceptible TB. Of the 46 children with TB treated under the Torres Strait Treaty, 27 (59\%) were cured or had completed treatment, 13 (28\%) returned to Papua New Guinea with an unknown outcome, and three $(7 \%)$ had died; one defaulted from treatment, one was not followed up, and one was still being treated.

\section{Discussion}

This study provides original, comprehensive and recent data on the epidemiological and clinical characteristics of $\mathrm{TB}$ in children in Australia. Paediatric cases of TB accounted for $5 \%$ of the total national TB case load, a finding similar to those of recent reports from other low-incidence settings. ${ }^{15-17}$ National rates of TB in children in Australia have not changed markedly over the past 10 years, consistent with the stable rate for the overall population. ${ }^{18}$

Our findings suggest that recent immigration has had a greater influence on the burden of TB in children than transmission within Australia. In most cases $(56 \%)$, the reported country of birth was outside Australia, and this proportion was higher than the corresponding figures for New Zealand, the United States and western Europe, where $26 \%-31 \%$ of patients with TB were born outside the respective country. ${ }^{16,17,19}$ The notification rate of 9.57 per 100000 overseas-born children per year is lower than the rate of 35-37 per 100000 overseasborn children reported for the United Kingdom (1999-2006) and the Netherlands (1993-2012). ${ }^{15,20}$ This difference may reflect the fact that there was no pre-migration screening in those countries during the reported periods, so that all cases were detected and notified after arrival.

Despite the strong link with recent immigration that we found, only a minority of children with TB $(8.7 \%)$ were detected by specific onshore post-arrival immigration screening. Passive case detection identified most cases, including the overseasborn children who were typically 
6 Notified cases of tuberculosis in overseas-born children, 2003-2012, by years since arrival in Australia

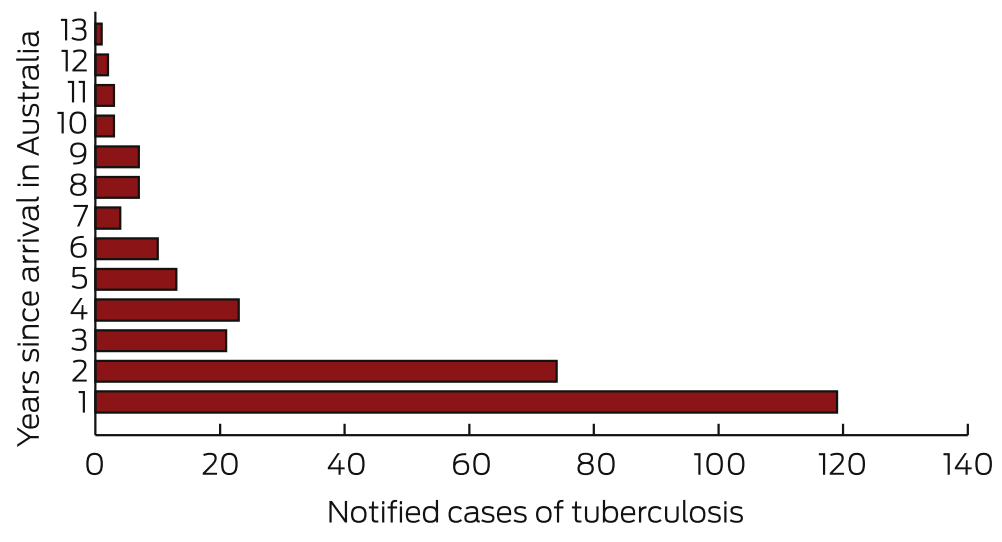

diagnosed within 2 years of their arrival. The frequency of post-arrival case detection may indicate that the offshore screening process is inadequate, ${ }^{21}$ or that most overseas-born children with TB did not have active disease at the time of their initial screening. This suggests that there is potentially a role for preventive therapy in immigrant children from high-incidence countries with latent TB infection (LTBI), which could be supported by introducing improved pre-migration screening of younger children. A chest x-ray is performed on all applicants for a permanent or provisional visa for Australia aged 11 years and over; in younger applicants, a chest $\mathrm{x}$-ray is performed only when there is a history of contact with $\mathrm{TB}$ or if clinically indicated by symptom screening. ${ }^{22}$ The case detection rate by immigration screening in Australia is higher in adult than in child immigrants. ${ }^{23}$ The lower detection rate for children probably reflects the epidemiology of TB, although it may also indicate an inadequate pre-migration screening process that is based largely on physical examination. The US has recently enhanced pre-migration screening of children aged 2-14 years in countries where the WHO estimates that TB incidence is at least 20 cases per 100000 persons by including screening for LTBI; this involves a tuberculin skin test or interferon- $\gamma$ release assay, which, if positive, is followed by a chest $x$-ray. ${ }^{24}$
Current opportunities for prevention that are supported by our findings include contact investigations. While BCG status was not reported for the cases we analysed, BCG vaccination of young children before they travel for extended periods to high-incidence countries could play a greater role. ${ }^{15,19,25} \mathrm{Op}$ portunities for prevention in at-risk children are often missed. ${ }^{15}$

The higher notification rate for Indigenous than for non-Indigenous Australian-born children is similar to the pattern reported for the general population. 6,26 In New Zealand, higher rates of $\mathrm{TB}$ were found in children of Pacific Island and Maori background than for other locally born children. ${ }^{19}$ An active program for diagnosing and treating LTBI in Indigenous people by contact, community, school and prison screening is one strategy used in some areas to better prevent and to ultimately eliminate TB. ${ }^{27}$ The complex nature of TB in Indigenous Australians has been discussed elsewhere. ${ }^{28}$

A large number of TB notifications were of children with refugee or humanitarian status or who used Australian medical care under the Torres Strait Treaty. It is recommended that all refugees, including children, be screened for LTBI and then referred to local $\mathrm{TB}$ services if a positive culture is obtained. ${ }^{29}$ This provides an opportunity for treating LTBI in refugee groups. The access of Papua New Guinea nationals, including children, to medical services in the Torres Strait Treaty Zone has recently become a major political and clinical management problem because of the high prevalence of MDR-TB in this population. $^{30}$

The strengths of our study include the fact that we ascertained cases from a national notifiable disease register containing data from all Australian jurisdictions. There are, however, potential limitations. Although we did not formally validate the recorded data, discrepancies were noted, suggesting that incorrect information may have been entered. Data were incomplete for some important variables, including the method of case detection and whether HIV testing was undertaken. The case detection method was unknown for $20 \%$ of cases, but recognition of $\mathrm{TB}$ in children is an important sentinel indicator of recent transmission. ${ }^{4}$ Further, it is not known whether the data on specimen submission for laboratorybased diagnosis were complete. Laboratory confirmation and drug susceptibility testing are important indicators of diagnostic accuracy, and epidemiological trends, including those for MDR-TB, also have implications for clinical management. Finally, while all Australian jurisdictions were included in our study, it has been shown in the UK that TB in children can be both under- and over-reported. ${ }^{31}$ This facet of the problem has not been assessed in Australia.

In conclusion, there is a low burden of paediatric TB in Australia, but the rate has not changed over the past decade. The highest rates are among children born overseas, emphasising the potential value of broadening pre-migration screening to further reduce the burden of TB in children in Australia.

Acknowledgements: We thank Christina Bareja, Cindy Toms and Mark Trungove (Australian Department of Health) for assistance with data interpretation, and members of the National Tuberculosis Advisory Committee and the NTAC Secretariat of the Department of Health for their support of this study.

Competing interests: No relevant disclosures.

(c) 2015 AMPCo Pty Ltd. Produced with Elsevier B.V. All rights reserved. 
1 World Health Organization. Global tuberculosis report 2014. Geneva: WHO, 2014. http://www.who.int/tb/ publications/global_report/en/ (accessed Sep 2015).

2 Dodd PJ, Gardiner E, Coghlan R, Seddon JA. Burden of childhood tuberculosis in 22 high-burden countries: a mathematical modelling study. Lancet Glob Health 2014; 2: e453-e459.

3 Donald PR. Childhood tuberculosis: out of control? Curr Opin Pulm Med 2002; 8: $178-182$.

4 Graham SM, Sismanidis C, Menzies HJ, et al. Importance of tuberculosis control to address child survival. Lancet 2014; 383: 1605-1607.

5 National Tuberculosis Advisory Committee of Communicable Diseases. The strategic plan for control of tuberculosis in Australia: 2011-2015. Commun Dis Intell Q Rep 2012; 36: E286-E293.

6 Toms C, Stapledon, R, Waring, J, Douglas P; the National Tuberculosis Advisory Committee, for the Communicable Diseases Network Australia, and the Australian Mycobacterium Reference Laboratory Network. Tuberculosis notifications in Australia, 2012 and 2013. Commun Dis Intell Q Rep 2015; 39: E217-E235.

7 McBryde ES, Denholm JT. Risk of active tuberculosis in immigrants: effects of age, region of origin and time since arrival in a low-exposure setting. Med $J$ Aust 2012; 197: 458-461. https://www. mja.com.au/journal/2012/197/8/riskactive-tuberculosis-immigrantseffects-age-region-origin-and-timearrival

8 Lucas M, Nicol P, McKinnon E, et al. A prospective large-scale study of methods for the detection of latent Mycobacterium tuberculosis infection in refugee children. Thorax 2010; 65: 442-448.

9 Australian Government Department of Health. Australian national notifiable diseases and case definitions [website]. http://www.health.gov.au/ internet/main/publishing.nsf/Content/ cdna-casedefinitions.htm (accessed Mar 2015).

10 Australian Bureau of Statistics. 3101.0 - Australian demographic statistics, Jun 2013 [website]. Canberra: ABS, 2013. http://www.abs.gov.au/ AUSSTATS/abs@.nsf/allprimary mainfeatures/61D19DFBD033B48
FCA257CA7000DCB16?opendocument (accessed Aug 2014).

11 Australian Bureau of Statistics. Migration, Australia, 2011-12 and 2012-13 [website]. Canberra: ABS, 2013. http://www.abs.gov.au/ AUSSTATS/abs@.nst/Productsby ReleaseDate/D6B1E6EFAC3F8BA3 CA257DDB000BD5D8?OpenDocument (accessed Oct 2014).

12 Australian Bureau of Statistics. 3238. 0 - Estimates and projections, Aboriginal and Torres Strait Islanders, 2001 to 2026 [website]. Canberra: ABS, 2014. http://www.abs.gov.au/ausstats/ abs@.nsf/mf/3238.0 (accessed Oct 2014).

13 Australian Bureau of Statistics. Aboriginal and Torres Strait Islander population projections, state/territory [website]. Canberra: ABS, 2014. http:// stat.abs.gov.au//Index.aspx? Queryld=1111 (accessed Sep 2014).

14 Australian Government Department of Health. National Notifiable Diseases Surveillance System [website]. Canberra: ABS. http://www9.health. gov.au/cda/source/cda-index.cfm (accessed Mar 2015).

15 Erkens CG, de Vries G, Keizer ST, et al. The epidemiology of childhood tuberculosis in the Netherlands: still room for prevention. BMC Infect Dis 2014; 14: 295.

16 Sandgren A, Hollo V, Quinten C, Manissero D. Childhood tuberculosis in the European Union/European Economic Area, 2000 to 2009. Euro Surveill 2011; 16: pii = 19825.

17 Winston CA, Menzies HJ. Pediatric and adolescent tuberculosis in the United States, 2008-2010. Pediatrics 2012; 130: el425-el432.

18 Australian Government Department of Health. National notifiable diseases: Australia's notifiable diseases status. Annual report of the National Notifiable Diseases Surveillance System. http://www.health.gov.au/ internet/main/publishing.nsf/content/ cda-pubs-annlrpt-nndssar.htm (accessed Sep 2015).

19 Howie S, Voss L, Baker M, et al. Tuberculosis in New Zealand, 1992-2001: a resurgence. Arch Dis Child 2005; 90: 1157-1161.

20 Abubakar I, Laundy MT, French CE, Shingadia D. Epidemiology and treatment outcome of childhood tuberculosis in England and Wales:
1999-2006. Arch Dis Child 2008; 93 : 1017-1121.

21 Denholm JT. Immigration screening for latent tuberculosis infection. Med J

Aust 2013; 199: 654. https://www.mja. com.au/journal/2013/199/10/ immigration-screening-latenttuberculosis-infection-0

22 Australian Government Department of Immigration and Border Protection. Fact sheet 22 - The health requirement [website]. http://www.border.gov.au/ about/corporate/information/factsheets/22health (accessed Sep 2015).

23 King K, Douglas PJ, Beath K. Is premigration health screening for tuberculosis worthwhile? Med J Aust 2011; 195: 534-537. https://www.mja. com.au/journal/2011/195/9/ premigration-health-screeningtuberculosis-worthwhile

24 US Department of Health and Human Services; Centers for Disease Control and Prevention. CDC immigration requirements: technical instructions for tuberculosis screening and treatment 2009. Oct 2009. http://www.cdc.gov/ immigrantrefugeehealth/pdf/ tuberculosis-ti-2009.pdf (accessed Jun 2015).

25 National Tuberculosis Advisory Committee. The BCG vaccine: information and recommendations for use in Australia. Commun Dis Intell Q Rep 2013; 37: E65-E72.

26 Bareja C, Waring J, Stapledon R. Tuberculosis notifications in Australia, 2010. Commun Dis Intell Q Rep 2014; 38: E36-E48.

27 Northern Territory Government. Guidelines for the control of tuberculosis in the Northern Territory. 4th ed. Darwin: Department of Health and Community Services, 2008. http:// health.nt.gov.au/library/scripts/ objectifyMedia.aspx?file=pdf/25/05 pdf\&sitelD=1\&str_title=Tuberculosis (accessed Sep 2015).

28 Devlin S, Passmore E. Ongoing transmission of tuberculosis in Aboriginal communities in NSW. N S W Public Health Bull 2013; 24: 38-42.

29 Murray RJ, Davis JS, Burgner DP; Australasian Society for Infectious Diseases Refugee Health Guidelines Writing Group. The Australasian Society for Infectious Diseases guidelines for the diagnosis, management and prevention of infections in recently arrived refugees: an abridged outline. Med J Aust 2009; 190: 421-425. 
https://www.mja.com.au/journal/2 009/190/8/australasian-societyinfectious-diseases-guidelinesdiagnosis-management-and

30 Majumdar SS, Marais BJ, Denholm JT, Britton WJ. Drug-resistant tuberculosis: collaborative regional leadership required. Med J Aust 2014; 200: 241242. https://www.mja.com.au/ journal/2014/200/5/drug-resistanttuberculosis-collaborative-regionalleadership-required
31 Teo SS, Alfaham M, Evans MR, et al. An evaluation of the completeness of reporting of childhood tuberculosis. Eur Respir J 2009; 34: 176-179. 